\title{
ASSOCIATION OF THE IMPACT OF POSTNATAL NUTRITION ON THE GROWTH OF PRETERM INFANTS <34 WEEKS GESTATIONAL AGE FROM BIRTH TO DISCHARGE
}

\author{
JITENDRA SINGH FAUJDAR ${ }^{1}$, KALPANA SINGH ${ }^{2}$, RAJVEER SINGH YADAV ${ }^{1 *}$, JITENDRA KUMAR GUPTA ${ }^{1}$, \\ MUNISH KAKKAR ${ }^{1}$, USHA ACHARYA ${ }^{1}$, SOURABH SINGH ${ }^{1}$
}

${ }^{1}$ Department of Paediatrics, MG Medical College and Hospital, Jaipur, Rajasthan, India. ${ }^{2}$ Medical Officer, State Government Hospital, Jaipur, Rajasthan, India. Email: drrajveer77@yahho.com

Received: 26 April 2020, Revised and Accepted: 16 June 2020

ABSTRACT

Objectives: The objectives of the study were to measure the actual daily amount of each nutrient (protein, glucose, and fat) energy and fluid as per current ESPGHAN guidelines for preterm infants and to analyze the role of nutrients at different gestational age on growth and weight of preterm infants.

Material and Methods: An observational and prospective cohort study was conducted from January 1, 2018, to December 31, 2018. This study included all preterm infants born $<34$ weeks gestational age admitted in the neonatal intensive care unit during this period at Mahatma Gandhi Medical College and Hospital. A total of 120 preterm neonates were studied.

Results: There were mean weight, length, and head circumference continues to rise till the study end. Mean energy at birth was also continues to rise till the end.

Conclusion: In the study, proper nutritional supplement as per ESPHAGEN guidelines was used for the development of preterm infant. The study showed that there were statistically significant results with anthropometry parameters with preterm baby growth in all domains.

Keywords: ESPGHAN, Energy, Neonates, Nutrients.

(C) 2020 The Authors. Published by Innovare Academic Sciences Pvt Ltd. This is an open access article under the CC BY license (http://creativecommons. org/licenses/by/4. 0/) DOI: http://dx.doi.org/10.22159/ajpcr.2020.v13i9.38460

\section{INTRODUCTION}

Preterm infant is defined as an infant born less than 37 weeks gestation. Preterm infants are classified according to their degree of prematurity. Extremely preterm infants are born less than 28 weeks, very preterm are born between 28 and $<32$ weeks, and moderate to late preterm are born 32 to $<37$ weeks. The number of preterm birth has been increasing in almost all countries, with more than 1 in 10 infants now born preterm worldwide [1]. The World Health Organization (WHO) has recently reported that the infant mortality rate in 2017, 4.1 million (75\% of all under-five deaths) occurred within the $1^{\text {st }}$ year of life. Globally, the infant mortality rate has decreased from an estimated rate of 65 deaths per 1000 live births in 1990 to 29 deaths per 1000 live births in 2018. In India, out of 27 million babies born every year (2010 data), 3.5 million babies born are premature. There is a large survival gap of preterm infants between low- and high-income countries. In high-income countries, $90 \%$ of infants born before 28 weeks survive compared to only $10 \%$ surviving in low-income countries [2].

Subcategories based on gestational age are a useful indicator as lower gestational age at birth is associated with increased mortality, disability, intensity of neonatal care, and cost. Late preterm infants do far better than infants of earlier gestational age although they are likely to experience more complications than term infants [3]. The advancement of neonatal medicine has resulted in increased survival rates of preterm infants [4]. Preterm infants are at particular risk of nutrient deficiencies, both during hospitalization and post-discharge. Infants with shortened gestational length miss out most important in utero accretion periods and are more likely to be born growth restricted, leading to greater utilization of nutrient stores for accelerated postnatal growth [5]. Preterm infants are also more likely to have medical problems or developmental delay [6]. The result is that many preterm infants will continue to be at risk of nutrient deficiencies after discharge from the neonatal intensive care unit (NICU). Nutritional support is often still required beyond hospital discharge but is not necessarily available.

Because every preterm is different, individualized planning and approaches are necessary to provide optimal nutritional management of the preterm infant. Such approaches include close monitoring of nutrientintake, feeding tolerance, and growth during hospitalization and growth after hospital discharge. Parents should be educated regarding warning signs of poor feeding/inadequate intake before discharge and early and frequent follow-up in an outpatient clinic should be scheduled until the infant demonstrates consistent, appropriate weight gains in the home environment. Any nutritional strategy implemented should recognize that preterm infants are a vulnerable population, at risk for short- and long-term sequel and that poor nutrition during the period of rapid brain growth (34-40 weeks gestation) may contribute to longterm neurodevelopmental problems.

Evidence-based standardized feeding guidelines have been published by different organizations such as ESPGHAN [7], the WHOCC, AIIMS, New Delhi [8], and American Academy of Pediatrics [9]. These guidelines cover parenteral, enteral, or combined nutrition.

The post-discharge nutrition of preterm infants is an understudied area. A lack of evidence in this area has meant that current recommendations for feeding preterm infants are based on the paucity of evidence available. Keeping this in view, we planned a prospective follow-up study to evaluate nutrient supply and growth outcomes of preterm infants born $<34$ weeks in response to a standard feeding protocol based on the ESPGHAN guidelines. There is also a lack of evidence on the effects of nutrition during early hospitalization on long-term growth outcomes. 
Aims and Objectives

The aims of the study were as follows:

- To measure the actual daily amount of each nutrient (protein, glucose, and fat) energy and fluid as per current ESPGHAN guidelines for preterm infants

- To analyze the role of nutrients at different gestational age on growth and weight of preterm infants

- To observe the growth pattern of preterm on enteral nutrition.

\section{METHODS}

The observational, prospective cohort study, present study, was conducted in the NICU of MGUMST, Jaipur, Rajasthan, during January 2018-December 2018. All preterm infants born <34 weeks admitted in the NICU MGMC during a 1-year period.

\section{Inclusion criteria}

- All preterm births (<34 weeks) were included in the study

\section{Exclusion criteria}

- Any congenital malformations, metabolic disorders, and conditions requiring surgical interventions

- Whose parents did not give informed consent

- Neonates on total parenteral nutrition (PN).

Due approval was taken from the Institutional Ethical Committee of Mahatma Gandhi Medical College, Jaipur, before undertaking the present study. Informed written consent was taken from the parent/ guardian before starting the study.

All preterm neonates were subjected to detailed clinical examination and gestational age was assessed by the last menstrual period and Ballard scoring system. Anthropometric parameters (weight, length, and head circumference $[\mathrm{HC}]$ ) were recorded with standardized technique (detailed method is explained in the materials and method section) from birth to discharge. Length and HC were measured weekly and weight was measured daily and plotted over preterm FENTON growth charts and gestational age calculated by Ballard scoring system. Data related to the actual daily nutrient requirement were calculated as per ESPGHAN guidelines. This was applied uniformly to all preterms focusing on the achievement of optimum growth in preterm infant.

Weight was recorded with weighing scale (subtract the weight of the towel).

Length of neonatal was measured by "Harpenden's infantometer."

HC was measured using a non-stretchable tape.

\section{Growth charts}

We used FENTON growth charts because it is a simple and effective way to monitor the growth. Serial plotting of weight, length, and HC on FENTON growth charts is compared with a reference standard. It helps us in early identification of growth faltering in infants.

\section{Dexolac special care infant formula}

Dexolac is powdered milk substitute. It is specially designed for the preterm neonates for overall growth and development

1. Strictly advised washing of hands thoroughly before preparing of feeds

2. We sterilize the feeding bowl and spoon by boiling in water for 10 $\min$

3. Boiled drinking water for $5 \mathrm{~min}$ and leave it till lukewarm

4. We poured $30 \mathrm{ml}$ of lukewarm water in bowl and mix it with $1 \mathrm{scoop}$ of Dexolac special care. In same proportion, amount of lukewarm water and scoops of Dexolac special care added.

\section{Statistical analysis}

The data were coded and entered into Microsoft Excel spreadsheet. Analysis was done using SPSS version 20 (IBM SPSS Statistics Inc., Chicago, Illinois, USA) Windows software program. Descriptive statistics included computation of percentages, means, and standard deviations. The repeated measures analysis of variance (for quantitative data within three groups) was used for quantitative data comparison of all clinical indicators. Level of significance was set at $\mathrm{p} \leq 0.05$.

\section{OBSERVATION AND RESULTS}

Mean gestational age in the present study was $31.17 \pm 1.22$ weeks with minimum and maximum gestational age of 30 and 33 weeks, respectively.

In the study, $58.3 \%$ male child ( $\mathrm{MCH})$ while $41.7 \%$ female child (FCH) in our study. Male and female ratio 1.4:1. Mean birth weight of babies was 1.18 with minimum and maximum BW of $0.96 \mathrm{~kg}$ and $1.5 \mathrm{~kg}$, respectively.

Mean length of stay in hospital was $3.57 \pm 1.08$ with minimum and maximum stay of 1 week and 5 weeks, respectively. About 33.3\% newborn was stay in hospital at least 3-4 weeks.

Mean score of full eternal nutrient was $7.79 \pm 1.83$ with minimum and maximum value of 6 and 15 , respectively.

According to weight, mean score was continuously increasing from birth to follow-up at 5 weeks which showed statistically significant results.

According to length, mean score was continuously increasing from birth to follow-up at 5 weeks which showed statistically significant results.

According to HCs, mean score was continuously increasing from birth to follow-up at 5 weeks which showed statistically significant results.

Mean protein requirement according to weight was continuously increasing from birth up to 5 weeks which showed statistically significant.

Mean fat requirement according to weight was continuously increasing from birth up to 5 weeks which showed statistically significant results.

Mean calorie requirement according to weight was continuously increasing from birth up to 5 weeks which showed statistically significant results.

\section{DISCUSSION}

The nutritional care for preterm newborns remains a challenge in clinical practice. Despite international feeding guidelines, in which it is recognized that human milk is the best source of nutrition for preterm infants [10], their implementation varies widely even for those born at 33-<37 weeks' gestation [11], who constitute $8-9 \%$ of all births, represent the vast majority of preterm infants [12], and remain at higher risk than their term counterparts.

In addition, there is no international consensus regarding how the growth of preterm infants should be monitored or what constitutes the ideal pattern of growth, including the period after they have reached term. This situation is even more unclear for those born very preterm (i.e., <32 weeks' gestation) [13], who are at the highest risk but only represent $10 \%$ of all preterm births.

The goal of nutrition management of very low birth weight (VLBW) infants is to achieve postnatal growth velocity that mimics intrauterine growth rates of the developing fetus. However, postnatal growth failure (GF), as defined by discharge weights below the $10^{\text {th }}$ percentile for corrected gestational age, has been reported at rates as high as $97 \%$ for VLBW infants [14]. GF is associated with long-term impairments in cognitive development and neurological outcomes [15], and promoting accelerated weight gain in preterm infants after a period of slow growth to "catch up" on standardized growth curves is associated with later risk for visceral adiposity, insulin resistance, and hypertension [16]. Thus, 
optimizing growth velocity to maintain intrauterine growth patterns and to avoid the need for catch-up growth is an integral component of the nutrition management of preterm infants.

Nutrition factors such as energy and protein deficit prolonged time on PN and delayed enteral feeds are independent predictors of GF, as are medical conditions such as low birth weight, chronic lung disease, corticosteroid exposure, and sepsis [17]. Although nutrition practices vary across NICUs, the nutrition course of all preterm infants involves phases of PN, enteral feeds, and the transitional period in between. PN is administered early to provide the initial nutrient requirement for growth [18].

PN helps to provide adequate amount of nutrients and improvement in growth and neurodevelopmental outcomes. It is started because of limitations to start enteral nutritional support due to immature gastrointestinal tract (GIT) [19]. Human milk is considered to be standard diet for infants, however, it should be fortified to meet requirements [20]. The American association paediatrics (AAP) and WHO recommendations suggest that if mother milk is not available, pasteurized donor breast milk should be provided as first alternative.

Studies have documented that necrotizing enterocolitis and bronchopulmonary dysplasia were significantly reduced in infants receiving human milk compared to infants who receive formula milk [21]. These effects are more prominent in premature neonates. Hence, the present study was planned to analyze the impact of postnatal nutrition on the growth of preterm infants $<34$ week gestational age from birth to discharge in a tertiary care NICU.

Mean gestational age in the present study was $31.17 \pm 1.22$ weeks with minimum and maximum gestational age of 30 and 33, respectively, in the present study. Kwok et al. [22] in their study titled "multicenter prospective observational study of feeding practices in 30-33 weeks preterm infants" reported similar gestational age. They reported that the median (interquartile range) gestational age was $32+3(31+1-$ $33+0$ ) weeks among the study subjects. Sanghvi et al. also revealed mean age of 31.8 weeks among the study subjects in their study [23].

In the present study, out of 120 born babies, $41.7 \%$ were female and $58.3 \%$ were male.

Miller et al. found $52 \%$ of the babies as males and rest as females [24]

In the present study, subject's mean length of stay was $3.58 \pm 1.08$. BW among the study subjects was $1.19 \pm 0.14$ in the present study. Sanghvi et $a l$. in their study reported that mean duration of stay (days) in hospital among the study subjects was $15 \pm 5.26$ [23]. Nangia et al. in their study found that mean duration of stay (days) in hospital among the study subjects was 14 [25].

In the present study, mean day required to reach adequate fluid, electrolyte, and nutrition was $7.79 \pm 1.84$ days with minimum and maximum days of 6 and 15, respectively. Sanghvi et al.in their study also revealed that mean time to regain birth weight in the study group was 5.52 \pm 2.94 days [23]. Nangia et al. in their study stated that days to regaining birth weight were $13.2 \pm 0.7$ [25]. The difference in time to regain birth weight though pleasant is difficult to explain. Whether a greater intake of even $40 \mathrm{kcal} / \mathrm{kg}$ in the study group in the initial days is crucial or whether oral intake of fluid causes better fluid retention remains to be proven.

When mean weight was compared statistically at different time intervals among the study subjects, it was found to be statistically significant. Mathew et al. in their study revealed that mean birth weight \pm SD was $1226.76 \pm 191$ [26]. Mean time $( \pm$ SD) to reach full volume feeds was $8.66 \pm 2.6$ days. Average time to regain birth weight was 14.2 days ( 2 weeks), with range from 12 to 17.6 days. A serial reduction in time to regain birth weights was observed with increasing gestational age. Maximum mean time to regain birth weight was in 28-week gestational age (17 days) and minimum time noted in 33week gestational age. A study from Chandigarh showed a growth velocity ranging from $15 \mathrm{~g} / \mathrm{kg} /$ day to $19.2 \mathrm{~g} / \mathrm{kg} /$ day in $29-30$ weeks and 33 weeks of gestation, respectively [27]. Growth charts by Saluja et al. showed a growth velocity of $15.18 \pm 1.7 \mathrm{~g} / \mathrm{kg} / \mathrm{d}$ [28], as compared to $16.24 \pm 2.37 \mathrm{~g} / \mathrm{kg} / \mathrm{d}$ in our study, despite using human milk fortifier (HMF) in the former study. Kumar et al. also mentioned using HMF/ preterm formula in extreme situations such as inadequate weight gain or insufficient breast milk [27].

When mean length was compared statistically at different time intervals among the study subjects, it was found to be statistically significant. Sanghvi et al.in their study found that mean length at discharge was $41.52 \pm 2.78 \mathrm{~cm}$ [23]. Visuthranukul et al. in their study showed that birth length was $33.7 \mathrm{~cm}$ which increases to $45 \mathrm{~cm}$ at discharge [29].

Table 1: Weight of infant at different time intervals

\begin{tabular}{lllll}
\hline Time & Mean \pm SD & Minimum & Maximum & p-value \\
\hline Birth & $1.16 \pm 0.11$ & 0.96 & 1.35 & $0.001(\mathrm{~S})$ \\
Week 1 & $1.08 \pm 0.13$ & 0.90 & 1.28 & \\
Week 2 & $1.203 \pm 0.11$ & 1.00 & 1.40 & \\
Week 3 & $1.27 \pm 0.28$ & 0.00 & 1.45 & \\
Week 4 & $1.42 \pm 0.08$ & 1.25 & 1.51 & \\
Week 5 & $1.44 \pm 0.03$ & 1.41 & 1.51 & \\
\hline
\end{tabular}

Table 2: Length of infant at different time intervals

\begin{tabular}{lllll}
\hline Time & Mean \pm SD & Minimum & Maximum & p-value \\
\hline Birth & $37.96 \pm 1.73$ & 34.80 & 41.00 & $0.001(\mathrm{~S})$ \\
Week 1 & $38.809 \pm 1.81$ & 35.50 & 41.80 & \\
Week 2 & $39.81 \pm 1.87$ & 36.00 & 42.80 & \\
Week 3 & $40.73 \pm 1.88$ & 36.70 & 43.40 & \\
Week 4 & $41.58 \pm 2.05$ & 37.20 & 44.20 & \\
Week 5 & $42.33 \pm 2.08$ & 38.00 & 44.90 & \\
\hline
\end{tabular}

Table 3: Head circumferences of infant at different time intervals

\begin{tabular}{lllll}
\hline Time & Mean \pm SD & Minimum & Maximum & p-value \\
\hline Birth & $27.79 \pm 1.08$ & 26.00 & 30.00 & $0.001(\mathrm{~S})$ \\
Week 1 & $28.43 \pm 1.11$ & 26.50 & 30.60 & \\
Week 2 & $29.16 \pm 1.06$ & 27.30 & 31.30 & \\
Week 3 & $29.86 \pm 1.12$ & 28.00 & 32.00 & \\
Week 4 & $30.73 \pm 1.37$ & 28.50 & 33.40 & \\
Week 5 & $31.62 \pm 1.51$ & 29.00 & 34.60 & \\
\hline
\end{tabular}

Table 4: Dose of protein of enteral feeding at different time intervals

\begin{tabular}{lllll}
\hline Time & Mean \pm SD & Minimum & Maximum & p-value \\
\hline Birth & $1.87 \pm 0.28$ & 1.60 & 2.90 & $0.001(\mathrm{~S})$ \\
Week 1 & $3.59 \pm 0.91$ & 1.40 & 4.42 & \\
Week 2 & $4.106 \pm 0.89$ & 1.80 & 5.00 & \\
Week 3 & $4.504 \pm 0.97$ & 2.00 & 5.40 & \\
Week 4 & $5.27 \pm 0.97$ & 3.10 & 6.50 & \\
Week 5 & $6.27 \pm 0.93$ & 4.50 & 7.60 & \\
\hline
\end{tabular}

Table 5: Dose of fat of enteral feeding at different time intervals

\begin{tabular}{lllll}
\hline Time & Mean \pm SD & Minimum & Maximum & p-value \\
\hline Birth & $3.72 \pm 0.35$ & 3.20 & 4.32 & $0.001(\mathrm{~S})$ \\
Week 1 & $7.24 \pm 1.61$ & 2.80 & 8.84 & \\
Week 2 & $8.17 \pm 1.66$ & 3.60 & 10.00 & \\
Week 3 & $8.9 \pm 1.8$ & 4.00 & 10.80 & \\
Week 4 & $9.88 \pm 1.98$ & 5.10 & 12.30 & \\
\hline
\end{tabular}


Table 6: Total calories (energy) requirement at different time intervals

\begin{tabular}{lllll}
\hline Time & Mean \pm SD & Minimum & Maximum & p-value \\
\hline Birth & $73.98 \pm 7.47$ & 64.00 & 86.00 & $0.001(\mathrm{~S})$ \\
Week 1 & $149.27 \pm 38.106$ & 56.00 & 184.00 & \\
Week 2 & $168.62 \pm 36.57$ & 74.00 & 203.00 & \\
Week 3 & $183.82 \pm 38.81$ & 82.00 & 217.00 & \\
Week 4 & $197.308 \pm 40.13$ & 90.00 & 232.00 & \\
Week 5 & $205.73 \pm 41.208$ & 95.00 & 240.00 & \\
\hline
\end{tabular}

When mean $\mathrm{HC}$ was compared statistically at different time intervals among the study subjects, it was found to be statistically significant. Sanghvi et al. in their study found that mean HC at discharge was $31 \mathrm{~cm}$ [23]. Visuthranukul et al. in their study showed that HC was 24.9 $\mathrm{cm}$ which increases to $32.8 \mathrm{~cm}$ at discharge [29].

When mean protein eternal was compared statistically at different time intervals among the study subjects, it was found to be statistically significant. Miller et al. in their study reported that from the parenteral to transitional phase, there were progressive decreases in both protein and protein/energy ratios as enteral feeds progressed by $10 \mathrm{~mL} / \mathrm{kg} / \mathrm{d}$, reaching a nadir of $2.1 \pm 0.5 \mathrm{~g} / \mathrm{kg}$ and $2.3 \pm 0.2 \mathrm{~g} / 100 \mathrm{kcal}$, respectively $(\mathrm{p}<0.05)$ [24]. Adjusted energy intakes remained comparable until PN was discontinued. With the discontinuation of PN, protein and energy intakes progressively increased as enteral feeds were advanced to goal $(\mathrm{p}<0.05)$. Enteral feeds volume during the PN portion of the transitional phase negatively correlated with total protein intake $(r=-0.69$; p <0.0001). Visuthranukul et al. [31] in their study revealed that mean protein at visit 1 (g/day) was $52.4 \mathrm{~g}$ which increased to $63.9 \mathrm{~g}$ at the second visit [29].

When mean fat was compared statistically at different time intervals among the study subjects, it was found to be statistically significant. Visuthranukul et al. in their study revealed that mean fat at visit 1 (g/day) was $47.8 \mathrm{~g}$ which increased to $53.4 \mathrm{~g}$ at the second visit [29]

When mean energy was compared statistically at different time intervals among the study subjects, it was found to be statistically significant. Visuthranukul et al. in their study revealed that mean energy at visit 1 (kcal/day) was 1251 which increased to 1396 at the second visit [29].

Our study has some limitations. It is a single-center study. We could not control for and ensure similar calorie intake by the two groups as the proportion of expressed breast milk and formula differed, but at discharge, all of the infants were on exclusive breastfeeding. We excluded unstable sick neonates, those who required positive pressure respiratory support and extremely LBW infants since these neonates may not be appropriate candidates for such feeding protocols.

\section{CONCLUSION}

Preterm birth is a medical emergency and early nutrition after birth is crucial for physical and neurodevelopment of baby. Preterm births are risk for nutritional compromise because of poor nutritional stores as well as physical (immaturity of GIT) and developmental characteristics (lack of suck, swallow, and breathe reflex).

In the study, proper nutritional supplement as per ESPHAGEN guidelines was used for the development of preterm infant. The study showed that there were statistically significant results with anthropometry parameters with preterm baby growth in all domains. All health professionals should acknowledge that preterm nutrition may be an emergency and need to improve their knowledge on when and how to achieve optimal feeds in them. There is a dare need through both clinical practice and research, to reduce nutritional deficits in these vulnerable neonates.

\section{AUTHORS' CONTRIBUTIONS}

I would like to express my heartiest gratitude to the participants, who gave willingness to participate in the study.

\section{CONFLICTS OF INTEREST}

There are no conflicts of interest.

\section{AUTHORS' FUNDING}

Self.

\section{REFERENCES}

1. World Health Organization. Born Too Soon: The Global Action Report on Preterm Birth. Geneva: World Health Organization; 2012.

2. World Health Organization Report: Available from: http:/www.who, int/gho/child health/mortality/neonatal infant text/en.

3. Behrman R, Butler A. Preterm Birth: Causes, Consequences, and Prevention. Washington, DC: The National Academies Press; 2007.

4. Conrad A. Post-discharge nutrition for the preterm infant. J Neonatal Nurs 2013;19:217.

5. Long H, Yi J, Hu P, Li Z, Qiu W, Wang F, et al. Benefits of iron supplementation for low birth weight infants: A systematic review. BMC Pediatr 2012;16:99-121.

6. Shah MD, Shah SR. Nutrient deficiencies in the premature infant. Pediatr Clin North Am 2009;56:1069-83.

7. Available from: http://www.espghan.org/guidelines/nutrition.

8. Chawla D, Thukral A, Agarwal R, Deorari A, Paul VK. AIIMSNICU Protocols 2008. Parenteral Nutrition. Division of Neonatology, Department of Pediatrics. Available from: https://www.newbornwhocc. org/2014_pdf/Parenteral\%20Nutrition\%202014.pdf.

9. American Academy of Pediatrics. Committee on nutrition: Nutritional needs of the preterm infant. In: Kleinman RE, editor. Pediatrc Nutrition Handbook. $6^{\text {th }}$ ed. Elk Grove Village/IL: American Academy of Pediatrics; 2009. p. 79-112.

10. Agostoni C, Buonocore G, Carnielli VP, De Curtis M, Darmaun D, Decsi T, et al. Enteral nutrient supply for preterm infants: Commentary from the European society of paediatric gastroenterology, hepatology and nutrition committee on nutrition. J Pediatr Gastroenterol Nutr 2010;50:85-91.

11. Harding JE, Cormack BE, Alexander T, Alsweiler JM, Bloomfield FH. Advances in nutrition of the newborn infant. Lancet 2017;389:1660-8.

12. Barros FC, Papageorghiou AT, Victora CG. International fetal and newborn growth consortium for the $21^{\text {st }}$ century. The distribution of clinical phenotypes of preterm birth syndrome: Implications for prevention. JAMA Pediatr 2015;169:220-9.

13. Cole TJ, Statnikov Y, Santhakumaran S, Pan H, Modi N; Neonatal Data Analysis Unit and the Preterm Growth Investigator Group. Birth weight and longitudinal growth in infants born below 32 weeks' gestation: A UK population study. Arch Dis Child Fetal Neonatal Ed 2014;99:F34-40.

14. Hayakawa M, Okumura A, Hayakawa F, Kato Y, Ohshiro M, Tauchi N, et al. Nutritional state and growth and functional maturation of the brain in extremely low birth weight infants. Pediatrics 2003;111:991-5.

15. Tan MJ, Cooke RW. Improving head growth in very preterm infants: A randomized control trial I: Neonatal outcomes. Arch Dis Child Fetal Neonatal Ed 2008;93:F337-41.

16. Uthaya S, Thomas EL, Hamilton G, Dore CJ, Bell J, Modi N. Altered adiposity after extremely preterm birth. Pediatr Res 2005;57:211-5.

17. Ehrenkranz RA, Younes N, Lemons JA. Longitudinal growth of hospitalized very low birth weight infants. Pediatrics 1999;104:280-9.

18. Hans DM, Pylipow M, Long JD, Thureen PJ, Georgieff MK. Nutritional practices in the neonatal intensive care unit: Analysis of a 2006 neonatal nutrition survey. Pediatrics 2009;123:51-7.

19. Thureen PJ, Hay WW. Intravenous nutrition and postnatal growth of micropremie. Clin Perinatol 2000;27:197-219.

20. Lucas A, Cole TJ. Breast milk and neonatal nectorising enterocolitis. Lancet $1990 \cdot 336: 1519-23$.

21. Schanler RJ, Lau C, Hurst NM. Randomized trial of donor human milk versus preterm formula as substitutes for mothers' own milk in the feeding of extremely premature infants. Pediatrics 2005;116:400-6.

22. Kwok TC, Dorling J, Ojha S. Multicentre prospective observational study of feeding practices in 30-33 weeks preterm infants. BMJ Paediatr Open 2017;1:e000040.

23. Sanghvi KP, Joshi P, Nabi F, Kabra N. Feasibility of exclusive enteral feeds from birth in VLBW infants $>1200$ g-an RCT. Acta Paediatr 
2013;102:e299-304

24. Miller M, Vaidya R, Rastogi D, Bhutada A, Rastogi S. From parenteral to enteral nutrition: A nutrition-based approach for evaluating postnatal growth failure in preterm infants. J Parenter Enteral Nutr 2014;38:489-97.

25. Nangia S, Vadivel V, Thukral A, Saili A. Early total enteral feeding versus conventional enteral feeding in stable very-low-birth-weight infants: A randomised controlled trial. Neonatology 2019;115:256-62.

26. Mathew G, Gupta V, Santhanam S, Rebekah G. Postnatal weight gain patterns in preterm very-low-birth-weight infants born in a tertiary Care Center in South India. J Trop Pediatr 2017;64:126-31.
27. Kumar S, Bhalla AK, Mukhopadhyay K. Postnatal percentile growth charts for Indian appropriate for gestational age (AGA) very low birth weight babies. Acta Paediatr 2012;101:e422-5.

28. Saluja S, Modi M, Kaur A. Growth of very low birth-weight Indian infants during hospital stay. Indian Pediatr 2010;47:851-6.

29. Visuthranukul C, Abrams SA, Hawthorne KM, Hagan JL, Hair AB. Premature small for gestational age infants fed an exclusive human milkbased diet achieve catch-up growth without metabolic consequences at 2 years of age. Arch Dis Child Fetal Neonatal Ed 2019;104:F242-7. 